\title{
Exploring the introductory physics classroom through the lens of intellectual humility: Handling what you do not know
}

\author{
Meagan Sundstrom $\oplus^{1}$ and Fabiana Cardetti $\odot^{2}$ \\ ${ }^{1}$ Laboratory of Atomic and Solid State Physics, Cornell University, Ithaca, New York 14853, USA \\ ${ }^{2}$ Department of Mathematics, University of Connecticut, Storrs, Connecticut 06269, USA
}

(Received 18 February 2021; accepted 22 September 2021; published 12 November 2021)

\begin{abstract}
The growing adoption of active learning techniques in physics courses requires that students productively engage in collaboration with their peers. Although studies in physics education research (PER) have addressed aspects of group work, the problem persists of how to engage students in collaborative work with appropriate self-awareness, adequate argumentation skills, openness to the views of others, and willingness to negotiate their ideas. In this article, we present intellectual humility (IH) as a new construct for PER to help advance our understanding and support of students' collaboration with peers. We particularly focus on authentic group work engagement, where students must handle their intellectual shortcomings during discussions in order to make sense of physics and solve problems. The aim of our work is to formally introduce the construct of IH from a limitations-owning perspective and report on the results of a mixed-methods study investigating students' learning experiences in introductory physics courses through an IH lens. The study provides quantitative evidence about how students gauge their own $\mathrm{IH}$ based on analysis of survey responses. We also provide an initial empirical foundation for facets of IH already present in the physics classroom from analysis of students' reflections and researchers' classroom observations. We find that students report high levels of love of learning, one characteristic of IH, however, our findings also point to students discomfort with intellectual limitations and inadequate handling of these shortcomings during group work. Our results suggest that students would benefit from learning spaces that welcome and encourage discussions around uncertainties, with minimal social risks that may be perceived as hindering their engagement.
\end{abstract}

DOI: 10.1103/PhysRevPhysEducRes.17.020135

\section{INTRODUCTION}

The driver for recent instructional change in physics is not merely to change students' views, but also for them to achieve genuine understanding of science and how science is done. Students in introductory physics courses often hold firm conceptions of what physics is, based on both their school experiences and life outside of the classroom. Oftentimes, however, these conceptions do not align well with the true nature of the discipline [1]. Introductory physics courses must challenge false conceptions and aim for students to not only acquire content knowledge, but also engage in science discovery through collaboration with peers [2]. Facilitating these actions in the classroom comprise the theory and educational reform movement known as active learning. Active learning benefits students' achievement gains across science, technology, engineering,

Published by the American Physical Society under the terms of the Creative Commons Attribution 4.0 International license. Further distribution of this work must maintain attribution to the author(s) and the published article's title, journal citation, and DOI. and mathematics (STEM) disciplines, having a significantly greater impact on student mastery of higher-level cognitive skills than traditional lecturing $[3,4]$.

In physics, active learning techniques require that students express their reasoning during group problem solving or conceptual activities, reflect on their own thinking, and/or engage with physical systems (e.g., laboratory experiments) in the learning process $[5,6]$. These learning initiatives align with the cooperative learning literature, which has shown that physics students who participate in collaborative groups create significantly better independent arguments than students who work alone [7]. Similarly, research on teaching strategies such as peer instruction and two-stage group exams has found that many groups outperform their highest-performing member $[8,9]$.

Though the benefits of group work within active learning have been examined extensively, there are many skills that students must develop to successfully navigate collaborative efforts with peers. Students must ask questions of their peers and educators and revise claims that are disputed in discussions [10]. Further, students must be open-minded in terms of hearing evidence that contradicts their perceptions, be willing to discard any original misconceptions in the 
face of such alternative evidence, and identify and pay appropriate attention to their intellectual limitations during academic conversations [11]. It is naive to assume that students will independently develop and master these skills in active learning settings. Instructors must effectively teach for and encourage such practices in the physics classroom.

The skillset mentioned above is germane to the construct of intellectual humility (IH), which refers to appropriately and effectively owning one's limitations [12]. We suggest that IH offers a new lens for physics education research (PER) scholars to examine the subtleties of student engagement in discussions with peers and find ways for instructors to better equip students for collaboration. Below, we review current literature in PER that relates closely to some of IH's defining characteristics and discuss how IH contributes to and helps expand this work.

\section{A. Handling uncertainty in collaborative scientific inquiry}

Recognizing the crucial role that addressing inconsistencies, ambiguity, and uncertainty plays in generating and sustaining scientific engagement, a number of PER scholars have studied how students navigate and negotiate uncertainties during peer collaboration. For example, Watkins and colleagues [13] present cases in which students who position themselves explicitly as not knowing something stimulate the engagement of peers in scientific inquiry. They argue that puzzlement and confusion can significantly contribute to learning physics and posit that students should embrace and value such uncertainty about physics concepts. This argument is confirmed by others, including Odden and Russ [14], who assert that students' verbalization of puzzlement is what allows them to enter epistemic games in which they begin the sensemaking process to construct understanding. They note that for students to be able to authentically participate in this process they "must engage in a certain amount of metacognitive reflection to pin down and articulate their gaps or inconsistencies in knowledge" (p. 14). These findings are in line with the broader literature on productive engagement in STEM learning. For instance, a study conducted by Koretsky and colleagues [15] highlights the disposition of the most successful groups to continuously and explicitly address gaps in their knowledge to help deepen their understanding.

The goal should then be to help every student reach a level of comfort with their intellectual limitations for successful engagement with their peers. In a way, metacognition with its focus on knowledge of cognition and regulation of cognition $[16,17]$ can support this endeavor. This high-order mental process allows students to become knowledgeable of themselves as learners, including understanding which learning strategies are effective, as well as when and why to use them. In addition, as noted by Odden and Russ [14], metacognition allows students to identify what they do not know by monitoring and evaluating their learning process, their allocation of resources, and their achievements in order to make informed decisions for effective control of their learning [18-20]. However, this self-oriented process is not sufficient to know how to voice and manage gaps in knowledge that affect collaborative work and do so in ways that can enable the group to make positive progress as urged by the literature $[13,15]$.

The productive disciplinary engagement (PDE) framework of Engle and Conant [21,22] provides a solid foundation for understanding the value of certain dispositions in supporting high quality scientific engagement. A group of students working together manifests the characteristics delineated in the PDE framework when their participation is responsive to one another, their engagement makes collective progress over time, and their conversations and actions align with established disciplinary discourse and norms. Further, these interactions are supported by four principles that are largely a product of the learning environment, including problematizing. Phillips and colleagues [23] consider problematizing as students identifying, articulating, and motivating the issue that needs to be resolved. Specifically, learners engage in problematizing as they become bothered or puzzled by some form of uncertainty. This may include uncertainty about the problem at hand, the ongoing work in the group, what they should do next, or whether their process or conclusions make sense.

Yet, research on social dynamics that take place in introductory physics problematizing contexts has demonstrated that students defer to various discursive resources when there are uncertainties in group discussions. Recent work investigating the specific activities students engage in while problematizing during inquiry-based physics labs found that some groups of students never articulate their uncertainties, even when their data provide an obvious contrast to their predictions [24,25]. Others found that when there is a clearly articulated mismatch in expertise among groupmates (e.g., one member is absent during the previous session and needs to catch up on the groups activities), members may position themselves with different levels of inchargeness or authority [26]. While the intent of taking charge may be to advance the group's work, it comes at the expense of other group members taking on a passive and noncontributing role. Additionally, some students may feel uncomfortable verbalizing uncertainties and defer to epistemic distancing. Conlin and Scherr [27] identify epistemic distancing as the act of hedging or phrasing claims as jokes or questions to avoid the possible social risks or personal discomfort that come with sharing ideas with peers. In this way, students may engage in group conversations while reducing their personal affiliation with the ideas they present. At the same time, managing limitations with epistemic distancing can open up space for productive sense-making sessions [27]. 
Thus, theory and research suggest that effective management of intellectual limitations matters for sustaining productive interactions during group work. Yet, evidence shows that students can struggle to recognize the detrimental effects of leaving knowledge gaps unattended and to appropriately engage in ensuing group conversations. Our collective understanding of why this process happens and how it can be remedied is underdeveloped. The present work addresses this issue by adapting a trait-level construct, intellectual humility, from existing literature to a new context to help explain students' management of their knowledge gaps in physics group work. Viewing student interactions through intellectual humility can help researchers explore why and how students defer to action-level discursive resources and offer guidance for instructors to support students' development of abilities to sensibly deal with inconsistencies, ambiguity, and uncertainty during collaboration.

In this paper, we operationalize the construct of intellectual humility by presenting the results of a mixedmethods study focused on students' learning experiences in introductory electromagnetism courses. Our work is organized as follows: First, we formally introduce intellectual humility, present the conceptualization that we adhered to in the study, and describe recent developments in this research field. Subsequent sections are focused on specific details of our research study, including a presentation and discussion of our findings from students' assessment of their own IH levels and indications of IH that emerge from both students' reflections about group work and researcher observations of physics classrooms. Our findings suggest that students' struggles with inconsistencies, ambiguity, and uncertainty during collaboration stem from their inability to strike a balance between being either too obsequious to what they do not know or too presumptuous about what they know.

\section{THEORETICAL FRAMEWORK: INTELLECTUAL HUMILITY AS OWNING LIMITATIONS}

In order to understand intellectual humility, it is important to first establish its relationship to the more general construct of humility, defined by researchers as involving "an accurate view of one's strengths and weaknesses" and "an interpersonal stance that is other oriented rather than self-focused" [28] (p. 226). As one may exhibit humility differently within a breadth of situations and contexts, scholars have proposed subdomains of humility to more accurately capture and study forms (e.g., behaviors and skills) of humility that are particular to specific situations [29]. The subdomain of intellectual humility narrows the focus of humility to predict behaviors in situations that pertain to one's knowledge and intellectual influence [30]. In these contexts, being right is deemed important and ideas are often negotiated and critiqued. In support of this view, intellectual humility has been found to be more predictive than general humility of dispositions and skills that pertain primarily to intellectual activities [29].

Several conceptualizations of intellectual humility have recently emerged in the research literature. We use the definition of intellectual humility proposed by Whitcomb and colleagues [12] as paying proper attention to and effectively owning one's limitations. The reference is to intellectual limitations, which encompass gaps in knowledge (e.g., not knowing the relationship between velocity and acceleration), mistakes (e.g., mixing up a positive and negative sign), and weaknesses in skills (e.g., insufficient mathematical skills to carry out a calculation). Owning one's limitations, then, refers not only to being aware of limitations, but also to admitting them to others (e.g., group mates) and to having an appropriate affective response to them in a given context (e.g., physics class).

To illustrate the definition further, consider the continuous spectrum shown in Fig. 1, on which the left side represents intellectual servility and the right side represents intellectual arrogance. An intellectually servile individual tends to hold strong self-doubt regarding their ability to succeed and underestimate or belittle their own intellectual skills. As a result and motivated by a need to gain social acceptance, the intellectually servile is prone to "enhancing the self-esteem of other people" [31] (p. 12). In this way, intellectually servile individuals place more value on others' truths, pay excessive attention to their own intellectual limitations, and allow these to overtake their emotions. On the other hand, one with intellectual arrogance is likely to be overconfident in their abilities, feel the need to be better than others to validate their self-worth, and maintain a defensive self-esteem. This results in a belief that "something must be true just because [they] thought of it" [32] (p. 83), a tendency to ignore both their own limitations and the limitations of others, and a tendency to dismiss their intellectual shortcomings [33,34]. Intellectual servility and intellectual arrogance are extrema on this spectrum, representing opposite views on one's intellectual limitations. Intellectual humility falls in the middle of this spectrum, as an intellectually humble individual is both aware and accepting of their personal limitations, modest about successes and achievements, and effectively attentive to their limitations $[35,36]$.

Scholarly work in intellectual humility, particularly research examining its role in education, is in its infancy, but research thus far has helped us begin to appreciate its potential. Deffler and colleagues [37] compared a group of 155 adults' completion of recognition tasks using a general humility scale and found that intellectually humble individuals may be more likely to retain and pay attention to new information. This may also align with the role of intellectual humility in the educational sphere, as students must learn and correctly apply new material to given problems and situations. In a more recent study, 


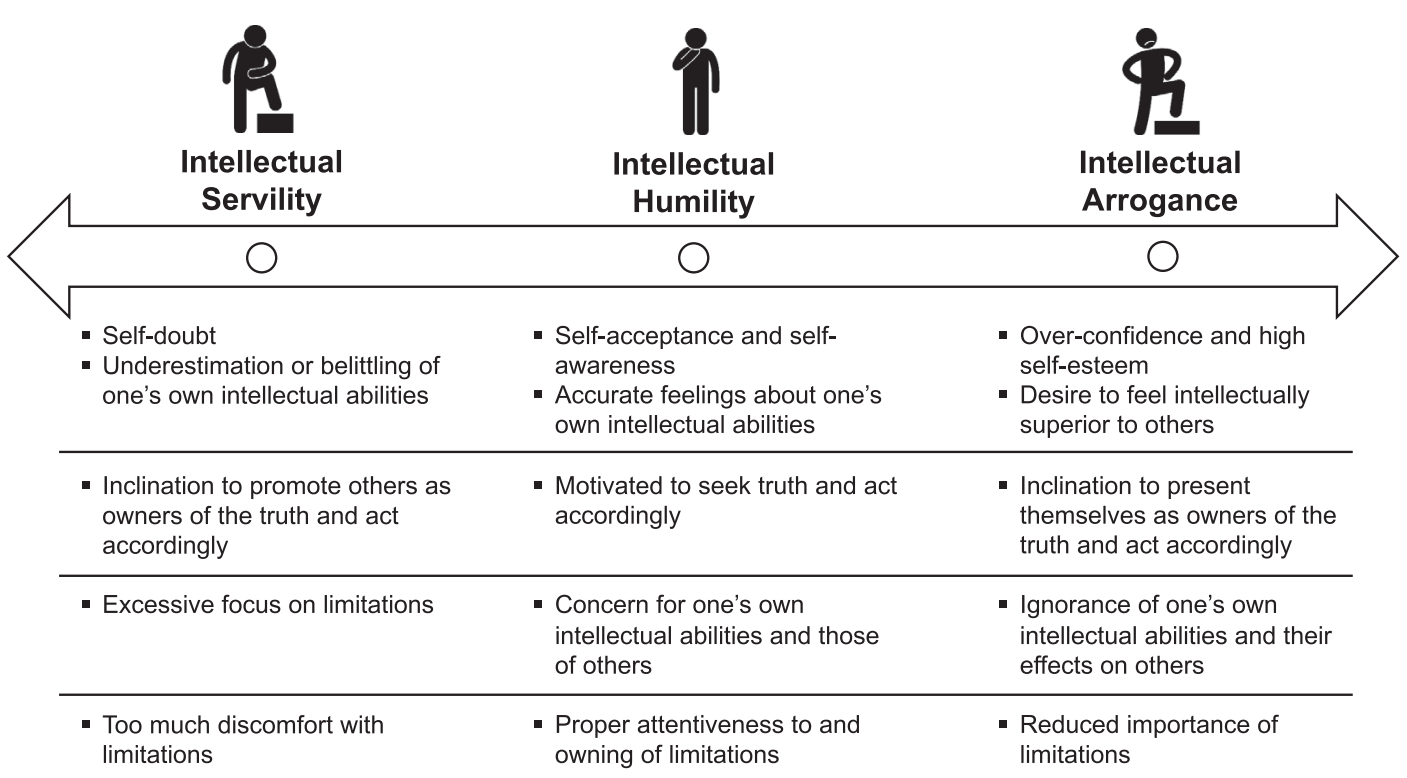

FIG. 1. Spectrum illustrating the characteristics of and relationship between intellectual humility and two extreme constructs: Intellectual servility and intellectual arrogance.

researchers found that intellectual humility relates strongly to a proper assessment and awareness of one's own knowledge, collaboration within learning environments, and intellectual openness [38]. The authors also suggest that intellectual humility directly influences the reasoning approaches, intrinsic motivation, and interpersonal dispositions of students.

In the realm of education, work has been done regarding the role of $\mathrm{IH}$ in moral education [39] and means of incorporating intellectual humility in college-level philosophy courses [40]. Yet, these studies are either bounded within the field of philosophy or simply rely on survey data with generic populations. To our knowledge, very few empirical studies examining intellectual humility in STEMspecific education settings have been conducted (see Ref. [41] as an example). We believe intellectual humility holds an important place in these specific learning environments and warrants further study at the interactional level, especially given active learning's increased emphasis on student collaboration.

Taking on the lens of intellectual humility for research studies requires ways in which we can measure or observe the construct in practice. Multiple surveys have been developed in an effort to achieve this operationalization [42-44]. Recently, a group of philosophers and psychologists [45] created a scale, which is directly grounded in the limitations-owning perspective that we follow [12], and assessed it through a series of studies. Their work yielded the following three defining factors of $\mathrm{IH}$ :

- Love of learning (LL): This factor captures the orientation of an intellectually humble individual to gain more knowledge and hold a better understanding of concepts - the pursuit of truth. The emphasis here is placed on a sincere internal motivation toward understanding beyond mere belief or opinion, aimed at obtaining epistemic goods. In Fig. 1, characteristics in the second line pertain to how an intellectually servile, humble, or arrogant individual manifests love of learning.

- Owning intellectual limitations (OIL): This factor focuses on the ability of the intellectually humble in accepting their limitations and in being mindful that these limitations affect both their understanding of content and their behaviors around others. Considering the third line of characteristics listed on the spectrum in Fig. 1, intellectually servile individuals focus too much on their limitations to the point where their mindset likely disrupts the learning process. Intellectually arrogant individuals gravitate toward ignoring their limitations and thus do not even consider the effects of their limitations on others (e.g., their peers during group work).

- Appropriate discomfort with limitations (ADL): This factor refers to an individual's attentiveness and emotional response to their limitations. Intellectually humble individuals will not only be aware of their individual shortcomings, but feel comfortable sharing them with others. In contrast, referring to the fourth line of characteristics in Fig. 1, intellectually servile individuals will hold too much discomfort-stress or embarrassment - over their limitations, while intellectually arrogant individuals will tend to diminish the importance of their limitations.

These three factors provide an organized scope of the different facets of intellectual humility and serve as the basis of our mixed-methods analysis in the current study. 


\section{OUR STUDY}

The limitations-owning conceptualization of intellectual humility offers a robust perspective that aligns with the current efforts in PER to improve students' learning of physics when working in collaborative settings. Building upon the knowledge and tools from the existing IH literature, we designed this study to explore how students engaging in peer interactions for physics learning may manifest aspects of IH and ultimately derive ways for instructors to support students during collaboration. Given the lack of empirical studies of this nature, our primary interest is to determine where students stand with respect to the three defining factors of the construct described above. Specifically, we aim to gather quantitative evidence about how students gauge their IH and provide an initial empirical foundation for facets of IH already present in the physics classroom. Toward these ends, the research questions guiding our study are

1. What is the self-assessed level of intellectual humility of introductory physics students with respect to the three defining factors?

2. In the context of students' introductory physics learning, how are defining factors of intellectual humility represented in reflections of their experiences and displayed during in-class behaviors?

To address these questions, we analyzed students' selfreports of IH via the previously described survey [45] as baseline quantitative data. We then examined students' written reflections about their physics learning experiences and performed classroom observations of physics group work settings to identify any indications of $\mathrm{IH}$ characteristics.

\section{METHODS}

In this section, we first describe the students and course contexts analyzed in this study. We then present our data collection and analysis methods for each data source, including how we dealt with disagreements in our qualitative work.

\section{A. Participants}

The participants for this study were students enrolled in two introductory electromagnetism courses for the fall 2018 semester (15 weeks) at a large, public research university in the northeastern United States. One course was a traditional, large enrollment, lecture-oriented physics course in which students attended three 50-min lectures in a stadium-style hall and one 3-h laboratory (lab) session each week. There were about 120 students in the lecture section of this course with about 18 students in each lab section. This course is intended for engineering majors. A professor in the physics department led the lectures, while one graduate student teaching assistant (TA) facilitated each lab section. The other course was an interactive, lowerenrollment course intended for students majoring in physics. About 30 students were enrolled in this course, which took place during three 2-h time periods each week in a studio-style classroom [46]. Lectures, engaged discussions, problem-solving sessions, and laboratory sessions were all integrated into these class times. The course was facilitated by a professor in the physics department and three graduate TAs, who each held different responsibilities but were all present and involved during all class sessions. The two courses covered very similar content using comparable presentation slides and syllabi.

Students from these two courses were asked to participate in our study voluntarily and anonymously. No course credit or compensation was given to participants. A subset of 48 of these students across the interactive class (18 students) and two different lab sections from the large-lecture class (30 students) consented to participate in our study. Although the two courses contained students in different majors and there was a difference in the number of enrolled students, the instructors agreed that the students in the two classes were comparable in terms of prior college experience (primarily first- and secondyear students), background knowledge for the course, and gender (majority of male students). We did not collect demographic information at the course level or from our participants, however we know that institution wide, for this particular academic year, $51 \%$ of undergraduates identified as female and $35 \%$ of undergraduates were minority students.

While we recognize that our sample of students may not contain a complete representation of all demographic groups, this was our limitation in carrying out the study in physics courses, which often contain homogeneous populations. Our choice of these courses was not to make comparisons between the two courses or among particular students, but rather to cast a wide net that captures the different settings experienced by our students to learn introductory physics. Moreover, selecting students from electromagnetism courses allowed us to evaluate students' $\mathrm{IH}$ in the context of university instruction rather than high school, which would have been the case in courses such as mechanics where results could inadvertently reflect students' recent school experiences.

\section{B. Data collection and analysis}

We selected a triangulation mixed methods design to address our research questions. These types of studies are characterized by the collection of different but complementary data on the same topic [47]. In our study, survey data is used to measure students' IH levels, while qualitative written response and observational data is used to glean indications of IH from students' impressions of their academic discussions and also from their actions in the classroom. Below, we describe our data collection and analysis methods for each of these data sources in light of each research question. 


\section{Intellectual humility survey}

To address our first research question, we administered the IH survey developed by Haggard and colleagues [45]. We chose this survey, with proven robust psychometric properties (e.g., overall Cronbach's $\alpha=0.86$ ), as it was created using the limitations-owning definition of $\mathrm{IH}$ and it distinguishes the three defining factors of $\mathrm{IH}$. The survey consists of 12 Likert-scale items to measure the three factors rated over a 5-point scale ranging from 1 (strongly disagree) to 5 (strongly agree), with some items negatively worded. Participants rate their agreement to statements such as "If I don't understand something, I try to get clear about what exactly is confusing to me" (love of learning), "When someone points out a mistake in my thinking, I am quick to admit that I was wrong" (owning intellectual limitations), and "When I think about the limitations of what I know, I feel uncomfortable" (appropriate discomfort with limitations). The full list of items can be found in the original paper by Haggard and colleagues [45].

All students who consented to participate in the study were invited to complete the survey, which was administered online using Qualtrics during the third week of the semester. The survey was completed by all 48 participants. With four survey questions per factor, this yielded $N=192$ responses for the love of learning and owning intellectual limitations factors. One student left one survey statement blank within the appropriate discomfort with limitations factor, so we excluded all of this student's responses within this factor, leaving $N=188$ responses. Following the guidelines from Haggard and colleagues [45], responses were reverse coded for negatively worded items, so all responses coded as 5 reflect the highest level of $\mathrm{IH}$ and all responses coded as 1 correspond to the lowest level of $\mathrm{IH}$. A confirmatory factor analysis of our samples' survey responses yielded moderate to high reliability for each of the three factors of IH: Love of learning (Cronbach's $\alpha=0.75$ ), owning intellectual limitations (Cronbach's $\alpha=0.71$ ), and appropriate discomfort with limitations (Cronbach's $\alpha=0.56$ ) [48].

We determined descriptive statistics for the survey responses without differentiating between the courses in order to gain a general scope of how introductory physics students self-assess their IH with respect to the three defining factors. Survey responses served as our primary data source for the first research question, providing broad baseline results to our research study.

\section{Written reflections}

We designed two open-ended questionnaires to address our second research question regarding how the three $\mathrm{IH}$ factors are represented in students' reflections about their academic discussions with peers. The questions did not make any reference to intellectual humility, but allowed participants to reflect and elaborate on how they both perceive and enact concepts related to IH in their physics course. The first round of questions (see Appendix A) was administered seven weeks into the semester and focused on how the classroom environment (broadly defined) influences student engagement in group work. The second round of questions (see Appendix B) was administered in the last two weeks of the semester and focused on how students engage in group work related to topics about which they are not certain. The questionnaires were administered by the researchers, not the professor or a TA, and students completed them in hand-written form by the end of class. Responses were anonymous, and students received no extra credit or any grades for completing them. Students provided phrases and/or complete sentences in response to each question. The total time to complete both questionnaires was between 20 and $40 \mathrm{~min}$.

In preparation for our content analysis, all hand-written reflections were transcribed in electronic form. The first phase of analysis started with an inductive approach where we independently read all students' reflections to gain a sense of the data as a whole [49] and determine first impressions, thoughts, and emerging labels for inductive codes [50]. We then met to discuss our ideas and create our initial coding scheme. We noticed students' writings brought up different topics in their responses, thus we decided our coding should be applied at the line or phrase level to capture the nuances in their insights. We created a codebook [51] with the preliminary codes, definitions, and illustrative examples identified from the data. Next, to reduce potential coder bias, we separately coded the data to test out our codebook and then met to discuss our coding results, revise the codebook for clarity, and ensure that the codes reflected key thoughts emanating from students' reflections. To gain stability of the coding protocol, we worked together to condense and relabel the initial codes, smoothing out redundancies and reflecting the complexity of students' thoughts that we noticed, while preserving what they voiced. This process resulted in a refined codebook in which each final code was narrowly defined to avoid overlapping meaning between codes. Since we coded the reflections at the line or phrase level, we allowed each student response to be tagged with multiple codes. To ensure the reliability of the findings, we employed negotiated discussions [52] to resolve any coding disagreements. For example, we had coding disagreements regarding two codes that we had labeled Peer Questioning and Seeking External Help. The disagreements stemmed primarily from the complexity of the responses and insufficient theoretical justification for differentiating between the two codes, which were consequently subsumed into a single code.

We then followed Hsieh and Shannon's [53] delineation of directed content analysis in which the limitationsowning perspective of IH guided the grouping of the codes within the three defining factors of IH. Reliability was maintained as we met regularly to discuss our results and 
negotiate revisions to the codebook and associations between codes and the three factors [52]. This analysis allowed us to identify patterns in the findings from the inductive analysis and to contextualize the codes [54] with respect to $\mathrm{IH}$, its defining factors, and the learning of introductory physics. Section V includes detailed excerpts from this data set that help to inform the reader and support potential transferability of our research findings [51].

In total, we collected 73 student reflections across the two administrations of the questionnaires. Inductive coding of all the written reflections yielded 27 initial codes. Four of those codes are omitted here because they do not hold tightly to the theoretical framework of IH used in this paper, especially in relation to student interactions. The remaining 23 codes were applied to the reflections. The directed content analysis resulted in a refinement of the codebook, which included the merging and relabeling of some codes as well as revision of definitions, rendering 15 final codes that each related to one of the three IH factors.

\section{In-class observations}

To complement the students' reflections and as a form of secondary data for our second research question, we conducted in-class observations of both courses. Since the two courses were taught in different instructional styles, we identified the laboratory and group problem-solving sessions of each course as the focus of our observations. As both contexts were conducive to collaboration, these sessions provided a suitable environment to study student interactions and identify instances of IH. We emphasize that the purpose of conducting observations was to find positive instances of $\mathrm{IH}$, as a preliminary proof of existence to show what the construct looks like in action. Our research questions are concerned with this evidentiary basis and not with the frequency of certain actions.

For three total class sessions, we collected careful observation notes that focused on students' behavioral gestures and verbal communications in the live classroom settings. Specifically, we walked around the room and jotted down notes of what students were working on (context), how they interacted with each other within groups and with other groups (behavior), and what they said to each other (verbal) in real time in instances where the groups engaged in negotiations or argumentation. We also noted nonverbal behaviors such as tone of voice, facial expressions, and other physical gestures that indicated a sense of uncertainty or other emotions. After the class period ended, we elaborated our jottings to more extensive, detailed notes that included complete sentences and phrases we heard and maps of where in the classroom the interaction occurred [55].

Our three observations took place in two sessions of the interactive course and one laboratory session of the traditionally taught course. All observations took place after the survey administration and in between the two reflection questionnaires, allowing us to capture how students manifest the construct of $\mathrm{IH}$ in the two course settings and throughout the entire semester. Table I summarizes the activities students completed and the course details of each of the observed sessions. We refer to the italicized activity names when we present the data in Sec. V.

Analogous to the written reflections, we analyzed the seven hours of classroom observation notes following first an inductive approach [56] where we carefully reviewed the observation notes for each lab, highlighting specific pages and flagging episodes within the sessions that struck us as relevant to the study. We discussed these initial ideas and continued to go back and forth through all the observation notes after each conversation. This process allowed us to break the data into bits of relevant information and to start to understand unique features of the lab sessions as well as regularities that cut across the labs and the written reflections [57]. Next, we coded the observation notes using the refined final codebook from the reflections analysis. Relating the two data sources via a common coding scheme allowed us to systematically capture the links between the findings from the students' reflections and what was observed in the classroom. Finally, the coded observational data were classified within the three factors of IH identified through the directed analysis of the students' reflections [53]. As a result of this final stage, we were able to more concretely address our second research question on the basis of both the self-reported content within the reflections and what we observed in the classroom.

Each data source provided complementary perspectives into how students instantiate aspects of IH in their physics learning experiences. Taken together, the three data sources

TABLE I. Summary of the classroom activities we observed.

\begin{tabular}{|c|c|c|}
\hline $\begin{array}{l}\text { Activity } \\
\text { name }\end{array}$ & Activity description & $\begin{array}{l}\text { Observation details } \\
\text { (course, session length, timing) }\end{array}$ \\
\hline Lorentz force & $\begin{array}{l}\text { Solving problems related to uniform magnetic fields in small } \\
\text { groups }\end{array}$ & Interactive course, $2 \mathrm{~h}$, eighth week of semester \\
\hline $\begin{array}{l}\text { Magnetic } \\
\text { flux }\end{array}$ & $\begin{array}{l}\text { Hands-on laboratory exploration of Faradays Law dropping masses } \\
\text { through a circular magnetic coil }\end{array}$ & $\begin{array}{l}\text { Traditional course, } 3 \mathrm{~h} \text {, eleventh week of } \\
\text { semester }\end{array}$ \\
\hline$R C$ circuits & $\begin{array}{l}\text { Hands-on laboratory exploration of the electromagnetic properties } \\
\text { of } R C \text { circuits using circuit boards and oscilloscopes }\end{array}$ & Interactive course, $2 \mathrm{~h}$, twelfth week of semester \\
\hline
\end{tabular}


provide a more comprehensive view of intellectual humility in introductory physics courses, while enhancing the validity and reliability of our results through triangulation [47].

\section{FINDINGS}

In this section, we present our findings in the context of each research question. We aim to offer an initial view into students' self-reported levels of IH and instantiations related to $\mathrm{IH}$ that students describe and exhibit in their learning of introductory physics.

\section{A. Self-assessment of intellectual humility}

Our first research question seeks baseline data of students' assessment of their own intellectual humility as they enter introductory physics classes in order to better understand our students' mindsets with respect to this construct. As mentioned earlier, we approached this task by administering an IH survey [45] at the beginning of the semester. The results of our descriptive analysis are summarized in Fig. 2, which displays stacked bar charts of the distributions of coded responses to the survey separated by each IH factor.

Love of learning statements have the highest mean value and the tightest distribution $(M=4.5, \mathrm{SD}=0.8)$. The majority $(90 \%)$ of LL responses indicate a reasonable or strong agreement (scores of 4 or 5) with these statements,

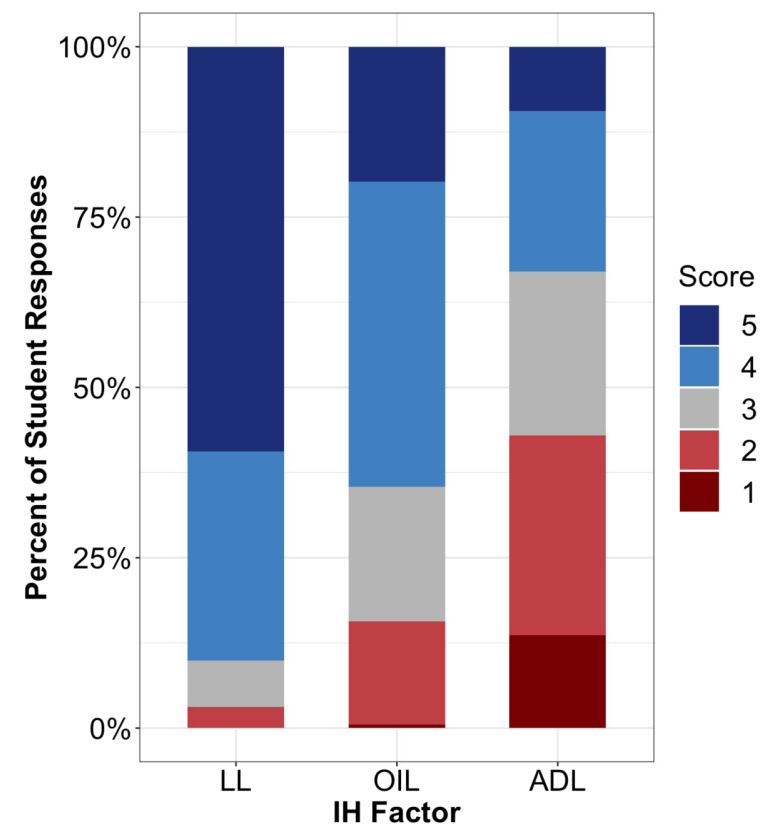

FIG. 2. Stacked bar charts displaying the distributions of survey responses for each $\mathrm{IH}$ factor. The height of each bar segment represents the percentage of student responses of that Likert value. For all statements, 5 is the most favorable response and 1 is the least favorable response from the limitations-owning definition of $\mathrm{IH}$. with no responses at the lowest IH level (score of 1). These results show that on aggregate, students have a substantially high level of LL as they enter their introductory electromagnetism course. The mean value related to the owning intellectual limitations statements is lower than that of $L L$ and the spread of responses is wider $(M=3.7$, $\mathrm{SD}=1)$. Responses to this factor's statements are slightly skewed toward the favorable end, with most (65\%) responses indicating reasonable to strong agreement (scores of 4 or 5). This evidence shows that on aggregate, students start these courses with a basic IH level of internal acceptance of intellectual limitations and ability to admit them to others. Finally, the appropriate discomfort with limitations statements receive the lowest mean response value and the widest distribution of responses $(M=2.9$, $\mathrm{SD}=1.2$ ). Responses for this factor are fairly symmetrically distributed about the neutral response (score of 3 ), with a large number of responses (42\%) at the lowest levels of IH (scores of 1 or 2). These scores place students at the lower end of the IH spectrum, characterized as intellectual servility (see Fig. 1), for the ADL factor.

\section{B. Intellectual humility in the physics classroom}

We addressed the second research question by analyzing the written reflections and classroom observation notes. This in-depth analysis allowed us to identify distinct sets of codes that aligned with each of the three factors of IH, which we present next. Since each of our codes capture an instantiation of the construct, from here on we refer to codes as instantiations.

\section{Love of learning}

As a result of our directed analysis, seven instantiations of IH were classified under the love of learning factor. In Table II, instantiations under this category are defined and supported with examples from the students' reflections and our observation notes (when available). The first six instantiations are closely related to $\mathrm{IH}$, while the seventh instantiation reveals a deficiency with respect to love of learning and falls toward the intellectual servility side of the spectrum in Fig. 1. Here, we provide a synthesis of these instantiations, positioning our findings in relation to the theoretical underpinnings of $\mathrm{IH}$.

Most (six) instantiations within love of learning communicated an intrinsic or behavioral motivation in students to gain understanding and acquire knowledge. These instances display features of curiosity that, as IH philosopher Whitcomb proposes, leads us to "recognize incoherencies among our beliefs, sustains our focus on those incoherencies, and motivates us to replace those incoherencies with newfound knowledge" [58] (p. 224). A clear pattern in all reflections featuring clarifying concepts was a personal aspiration to better understand the material, which was also identified in our classroom observations in the form of verbal requests for clarification. Our evidence 
TABLE II. Definitions and examples of instantiations related to love of learning.

\begin{tabular}{|c|c|c|}
\hline Instantiation & Definition & Examples \\
\hline $\begin{array}{l}\text { Clarifying } \\
\text { concepts }\end{array}$ & $\begin{array}{l}\text { Students describe a need to clarify } \\
\text { physics knowledge for personal } \\
\text { understanding of the material. }\end{array}$ & $\begin{array}{l}\text { 'I ask my groupmates my exact question where I'm confused to try and } \\
\text { better understand.' [Student reflection] } \\
\text { Recognizing students' reluctance to compute the cross product for the } \\
\text { Lorentz force, the instructor began showing them how to do it when } \\
\text { a student said aloud, 'I'm taking linear algebra right now and I know } \\
\text { how to do this. But how you're doing this is hard to understand } \\
\text { because it's your way of doing it and I am confused. Can you do it } \\
\text { symbolically?' The instructor responded by adjusting to a symbolic } \\
\text { explanation of the cofactor expansion. [Observation: Lorentzforce] }\end{array}$ \\
\hline Fixing a mistake & $\begin{array}{l}\text { Students identify a desire to resolve } \\
\text { mistakes or misunderstandings } \\
\text { during problem solving. }\end{array}$ & $\begin{array}{l}\text { '[The homework set up] makes it extremely difficult to learn because it } \\
\text { usually does not help you whatsoever when you get a question } \\
\text { wrong.' [Student reflection] }\end{array}$ \\
\hline $\begin{array}{l}\text { Seeking } \\
\quad \text { external help }\end{array}$ & $\begin{array}{l}\text { Students describe a means of learning } \\
\text { or filling a knowledge gap by } \\
\text { drawing on outside sources. }\end{array}$ & $\begin{array}{l}\text { '[As a group, we] would try to solve problems by looking through } \\
\text { notes or online search.' [Student reflection] } \\
\text { 'I like it when my peers ask questions that result from trying to build } \\
\text { their physical intuition.' [Student reflection] } \\
\text { While collecting data and viewing graphs on the computer, one group } \\
\text { was confused and could not understand how the data on their } \\
\text { computer screen corresponded to their physical dropping of the } \\
\text { weight through the coil. Clicking around on their graphs, one group } \\
\text { member blurted, 'I honestly have no clue... we should ask [the TA] } \\
\text { for help.' After discussing with the TA, the students expressed } \\
\text { understanding and moved on with the next steps to complete the lab. } \\
\text { [Observation: Magnetic flux] }\end{array}$ \\
\hline Openness & $\begin{array}{l}\text { Students describe a willingness to } \\
\text { listen to and consider the thoughts } \\
\text { of others. }\end{array}$ & $\begin{array}{l}\text { 'I'm always open to their reasoning. I will understand the concept } \\
\text { better (if proven wrong).' [Student reflection] } \\
\text { Groups were keen to offer each other assistance with the experimental } \\
\text { setup and sense-making of the data output on their oscilloscopes. } \\
\text { [Observation: } R C \text { circuits] }\end{array}$ \\
\hline $\begin{array}{l}\text { Analyzing } \\
\text { evidence }\end{array}$ & $\begin{array}{l}\text { Students describe the role of analyzing } \\
\text { and evaluating their evidence in } \\
\text { solving a problem. }\end{array}$ & $\begin{array}{l}\text { 'We will each explain our strategy and sometimes will try both to see } \\
\text { which seems more right. Sometimes one of our approaches falls } \\
\text { apart part way through trying it.' [Student reflection] } \\
\text { A student skeptical of the numerical results he was obtaining, and } \\
\text { unable to decipher the results on his own, asked out loud, 'Where is } \\
\text { this } 10^{4} \text { coming from?' A member of another group traced back } \\
\text { through each step of the students' work and pointed out that the } \\
\text { magnitude of the answer was off by a certain factor due to unit } \\
\text { conversion, Volts, which helped ease the confusion and move the } \\
\text { conversation forward. [Observation: } R C \text { circuits] }\end{array}$ \\
\hline Argumentation & $\begin{array}{l}\text { Students discuss the role of } \\
\text { argumentation, explaining each } \\
\text { other's opinions and methods and } \\
\text { then critiquing and choosing the } \\
\text { best one, during group work. }\end{array}$ & $\begin{array}{l}\text { 'Upon disagreement among group members, each will argue [their] } \\
\text { point and also hear the other side and work to a compromise.' } \\
\text { [Student reflection] } \\
\text { A group compared their oscilloscope readings to those of other groups } \\
\text { sitting near them. One student said, 'That looks better than ours.' } \\
\text { Another replied, 'Yours makes sense.' The students hashed out } \\
\text { which of the groups readings displayed the correct graph, explaining } \\
\text { each other's results and approaches and providing feedback to one } \\
\text { another. This allowed students to make better sense of their data by } \\
\text { reasoning through physics concepts that informed what the graph } \\
\text { should look like. [Observation: RC circuits] }\end{array}$ \\
\hline $\begin{array}{l}\text { Focusing on } \\
\quad \text { correct answers }\end{array}$ & $\begin{array}{l}\text { Students identify that getting the } \\
\text { correct final answer is a priority of } \\
\text { in-class group work. }\end{array}$ & $\begin{array}{l}\text { 'Whatever the right answer [is], we should be agreeing on that.' } \\
\text { [Student reflection] }\end{array}$ \\
\hline
\end{tabular}


suggests that students' desire to gain knowledge about physics concepts pushes them to confront their own intellectual limitations in front of a small group or an entire class. Relatedly, students also desired to correct mistakes or misunderstandings during problem solving. While students' focus on fixing a mistake can be misconstrued as an obsession over potential grade penalties, our students' reflections generally indicated that resolving mistakes was in the interest of overcoming knowledge gaps.

Reflections also revealed students' positive disposition for seeking external help by reaching out to instructors or online resources as means for subduing limitations that may obstruct their learning. In classroom observations, we noticed students referencing their notes, searching online, or initiating interactions with the instructor, using questioning as an instrument for learning and understanding. Such actions are consistent with the tendency of the intellectually humble to defer to knowledgeable others when faced with shortcomings in content knowledge [12].

Moreover, our analysis helped us capture instances of students' openness to consider the ideas of others and a propensity for considering counterarguments to their own convictions, both of which serve as an asset to learning. In our observations, we noted that students were willing to listen not only to their own groupmates, but also to the ideas of other groups, as a means of enhancing their own group's understanding. This tendency is related to openmindedness, which Spiegel connects tightly to intellectual humility, arguing that "they properly build off one another in the virtuous mind" [59] (p. 36).

Other instantiations further underlying students' openminded approaches included analyzing evidence. Students described a tendency in themselves or within their group to carefully investigate their steps as part of furthering their understanding of physics problems. In the classroom, we noticed that skepticism toward unclear results prompted one group of students to trace back their steps and theoretically calculate the voltage through a particular circuit setup, which led to conceptual understanding in this particular case.

We also identified argumentation as expounding students' interest in discerning the validity of their individual approaches when working with others. Students emphasized their interest in engaging in argumentation to listen to diverging views and the rationale behind them so as to choose one that all group members could understand under general consensus. In the classroom, we observed students carefully going through their methods especially when there were several ideas at hand, working with others to find the best strategies, and revising their personal methods accordingly. Relatedly, IH scholars assert that, encouraged by a love of learning, an intellectually humble individual is more prone to revise their personal beliefs upon learning of defeaters [12] and persist in the pursuit of knowledge in spite of opposition.
Finally, we uncovered instances of students focusing on correct answers, which to an extent aligns with the definition of love of learning as one's caring about truth and knowledge. However, some students indicated neglect for the process of arriving at the solution, which from the lens of IH is not favorable. Intellectual humility embraces the pursuit of correct answers, but correct is not the absolute aim as is the pursuit of an answer. On the other hand, an intellectually servile individual cares about the truth, but they hold no regard for where the truth comes from or how it was found.

\section{Owning intellectual limitations}

Following the same approach as with the previous factor, Table III showcases the five instantiations of OIL and their corresponding definitions and examples from reflections and observations (when applicable). Three of these instantiations correspond strongly with IH and two instantiations lean toward the right end of the spectrum in Fig. 1, indicating intellectual arrogance. Here, we describe the connections and differences across instantiations and tie these findings to the limitations-owning perspective of $\mathrm{IH}$.

The first three instances of owning intellectual limitations conveyed students' inclinations toward acceptance and admittance of limitations when working collaboratively with others, which can be situated close to the center of the spectrum in Fig. 1. When at loss in a group conversation, students exhibited a willingness for identifying knowledge gaps, or recognizing their intellectual limitations. This is important for $\mathrm{IH}$, since the first step toward identifying specific voids in one's knowledge is the recognition that knowledge certainty in absolute terms is impossible.

Moving a step further, students also commented about the need for articulating shortcomings to be able to move forward with group work, which we captured as admitting knowledge gaps. Students pointed out that making limitations visible not only benefits the group's productivity, but also one's own understanding. We also observed students' courage to put themselves in a vulnerable position in front of their peers when orally admitting their limitations. When their approach was challenged or proven incorrect during group work, students expressed an inclination toward reconsidering ideas. Students described that in such situations, they would cautiously rethink and, if needed, revise their approach after listening to others. Reflections showed no indication of students' resentment toward being called out, on the contrary they portrayed a sense of acceptance that they could be missing something important in their reasoning.

In contrast, the final two instantiations in Table III coincide with intellectual arrogance. Some students described a tendency for pretending to know upon recognizing their limitations during group work, so as to conceal their gaps in knowledge by deceiving their peers. These reactions conflict with $\mathrm{IH}$, as successfully owning 
TABLE III. Definitions and examples of instantiations related to owning intellectual limitations.

\begin{tabular}{|c|c|c|}
\hline Instantiation & Definition & Examples \\
\hline $\begin{array}{l}\text { Identifying } \\
\quad \text { knowledge gaps }\end{array}$ & $\begin{array}{l}\text { Students describe a willingness } \\
\text { to identify knowledge gaps as } \\
\text { part of the learning process. }\end{array}$ & $\begin{array}{l}\text { 'I have no pride for my methods until they are proven to be correct, so when I am } \\
\text { wrong I am eager to find out why.' [Student reflection] } \\
\text { 'I try to figure out exactly what I do and don't know, then build from there.' } \\
\text { [Student reflection] }\end{array}$ \\
\hline $\begin{array}{l}\text { Admitting } \\
\quad \text { knowledge gaps }\end{array}$ & $\begin{array}{l}\text { Students acknowledge the value } \\
\text { in admitting to others a gap in } \\
\text { their knowledge. }\end{array}$ & $\begin{array}{l}\text { 'I wish my peers could recognize that being confused is a good thing.' [Student } \\
\text { reflection] } \\
\text { A student presented his solution on the whiteboard in front of the TA and his } \\
\text { group. In explaining his solution, he recognized that his final answer was off } \\
\text { by a factor of } 1000 \text {. He admitted, 'I messed up somewhere somehow, but I } \\
\text { don't know.' Another member of the group pointed out that the student used } \\
\text { grams as a unit of mass instead of kilograms, resolving the incorrect } \\
\text { magnitude of the answer. [Observation: Lorentz force] }\end{array}$ \\
\hline $\begin{array}{l}\text { Reconsidering } \\
\quad \text { ideas }\end{array}$ & $\begin{array}{l}\text { Students describe reconsidering } \\
\text { their ideas about a problem, } \\
\text { upon their approach being } \\
\text { challenged or proven wrong. }\end{array}$ & $\begin{array}{l}\text { 'I reconsider my understanding of the topic and re-work through problems to } \\
\text { better understand [them].' [Student reflection] } \\
\text { Often, TAs would not directly answer student questions, rather they would } \\
\text { nudge students in the right direction and encourage them to reflect about their } \\
\text { reasoning with their group mates. It is notable that students in general paused } \\
\text { during their lab experiment or problem solving when their methods were } \\
\text { challenged, taking the time to re-work and revise their approach. } \\
\text { [Observation: Lorentz force] }\end{array}$ \\
\hline $\begin{array}{l}\text { Pretending to } \\
\quad \text { know }\end{array}$ & $\begin{array}{l}\text { Students discuss a tendency to } \\
\text { pretend that they know the } \\
\text { course content when exposed } \\
\text { to their limitations in } \\
\text { academic conversations. }\end{array}$ & 'I pretend to know for a while til a TA comes by.' [Student reflection] \\
\hline Superiority & $\begin{array}{l}\text { Students describe the impact } \\
\text { that an attitude of superiority } \\
\text { over others has on academic } \\
\text { conversations. }\end{array}$ & $\begin{array}{l}\text { 'If [my groupmate is] rude or try to make themselves superior, I kind of stop } \\
\text { listening. But if they are willing to help me understand I will learn from them } \\
\text { better.' [Student reflection] } \\
\text { Only one of three students in a group was using the lab equipment and the } \\
\text { group's desktop computer to complete the task at hand, in addition to leading } \\
\text { the conversation. Although this student was not overly assertive in his speech, } \\
\text { he pushed the group forward by helping them recognize the need to engage in } \\
\text { the lab and make progress. This student dominated the content and flow of the } \\
\text { discussion and the execution of the experiment. The other two students in the } \\
\text { group very slowly engaged as the lab proceeded, however the lead student } \\
\text { was gaining all of the learning experience collecting and analyzing data and } \\
\text { writing up the results. [Observation: Magnetic flux] }\end{array}$ \\
\hline
\end{tabular}

limitations "reduces both a person's propensity to pretend to know something when he doesn't and his confidently answering a question whether or not he knows the answer" [12] (p. 14). Students also described the negative impact of group members displaying a stance of superiority over others. Students indicated that they were unlikely to engage with peers who portrayed themselves in this way, as such behaviors hinder productive social dynamics. An attitude of superiority may convey disrespect to others who are perceived as intellectual inferiors and show no selfregulation of intellectual arrogance to present ideas in a nonoffensive manner [30]. In this vein, we observed in the classroom that one member of a small group took charge of the experiment. Other students in the group were fairly quiet and eventually freeloaded, getting credit for work they did not do. Another side to superiority that students described, however, is a readiness to overlook this superiority attitude from a peer provided it was accompanied by a disposition to let others in on what they presumably know better. This stance reflects a side of $\mathrm{IH}$ that is highlighted by Porter and Schumann, namely, that IH includes "a willingness to appreciate others' intellectual strengths" [60] (p. 140).

\section{Appropriate discomfort with limitations}

Finally, we categorized three instantiations under the appropriate discomfort with limitations factor of $\mathrm{IH}$, each of which is defined and illustrated with examples from student reflections and observation notes in Table IV. 
TABLE IV. Definitions and examples of instantiations related to appropriate discomfort with limitations.

\begin{tabular}{|c|c|c|}
\hline Instantiation & Definition & Examples \\
\hline Emotions & $\begin{array}{l}\text { Students describe how they feel } \\
\text { after their approach is either } \\
\text { challenged or proven wrong } \\
\text { during group work. }\end{array}$ & $\begin{array}{l}\text { 'I feel a bit stupid but feeling stupid makes me learn.' [Student reflection] } \\
\text { 'A little upset, but acceptable.' [Student reflection] } \\
\text { 'Anxiety.' [Student reflection] }\end{array}$ \\
\hline $\begin{array}{l}\text { Change in } \\
\text { confidence }\end{array}$ & $\begin{array}{l}\text { Students describe feeling either } \\
\text { a gain or loss of confidence } \\
\text { during an academic } \\
\text { conversation where they are } \\
\text { not certain about their } \\
\text { approach. }\end{array}$ & $\begin{array}{l}\text { 'I feel a loss of confidence and try to think about why I was wrong and why the correct } \\
\text { approach is correct.' [Student reflection] } \\
\text { A student solved a problem on the whiteboard and used the wrong units of mass, } \\
\text { leading to the wrong answer. After a classmate voiced the inaccuracy in his solution, } \\
\text { the student who was presenting his approach made an audible sighing sound, } \\
\text { lowered his head, and brought his shoulders down. [Observation: Lorentz force] }\end{array}$ \\
\hline Engagement & $\begin{array}{l}\text { Students describe how they } \\
\text { engage in group discussions } \\
\text { about a topic they are not } \\
\text { confident in. }\end{array}$ & $\begin{array}{l}\text { 'Doesn't affect my engagement, I will always try to engage so I can understand } \\
\text { material.' [Student reflection] } \\
\text { 'I tend to let other people contribute more after [noticing my own flaws]. I like to } \\
\text { withdraw and listen.' [Student reflection] } \\
\text { One student said to another group, 'Do you want me to set that up for you? We set it up } \\
\text { differently, but I don't know if it's right.' [Observation: } R C \text { circuits] }\end{array}$ \\
\hline
\end{tabular}

The first two instantiations of this factor align with the characteristics of an intellectually humble individual. The third instantiation captures two distinct preferences that can be taken to align with different ends of the IH spectrum (see Fig. 1). Here, we provide a more detailed description and relate our findings to the construct of $\mathrm{IH}$.

The first two instantiations of appropriate discomfort with limitations reveal students' internal perceptions of their limitations, particularly their emotional and affective response to knowledge gaps. First, we uncovered a range of students' Emotions in response to having their method or opinion proven wrong in a discussion. Students expressed appropriate levels of comfort and attentiveness rather than being excessive. This is largely in agreement with favorable epistemic beliefs associated with intellectual humility, as an individual "with $\mathrm{IH}$ is disposed to regret, but not be hostile, about her limitations, and more generally, to affectively respond to her limitations as the context demands" [12] (p. 518).

We also captured students' change in confidence when engaging in group work about a topic they do not understand well or for which views run counter to their own. Our findings point primarily to a loss of confidence, which may be taken as a negative result. However, according to Whitcomb and colleagues [12], an intellectually humble individual is more likely to reduce confidence in a belief for which there are defeaters.

Lastly, two distinguishable preferences emerged from our analysis for students' engagement in discussions about an uncertain topic. Some students initiate or actively engage in discussions even when they do not know enough about a topic (indicating intellectual arrogance), while under similar circumstances, other students become hesitant to participate in the discussion (potentially indicating intellectual servility). We elaborate on the implications of each of these preferences in the next section.

\section{DISCUSSION}

In this article, we advance intellectual humility as a construct to be used in PER to analyze both the internal (trait-based) and external (social) mechanisms through which students manage group work interactions about dissenting ideas or topics with which they are not sufficiently skilled. Using the three defining IH factors as a basis for our analysis, we identified specific internal and external characteristics already in use by introductory electromagnetism students. This study serves as a catalyst for further research that leverages this construct and its factors as a structure for systematic analysis to fulfill our incomplete understanding of group work and to illuminate decisions for classroom intervention.

The results of our survey analysis suggest that students may not know how to appropriately engage in the peer collaborations that active learning strategies often require $[2,5,6]$, particularly when they are uncertain about their understanding of a topic. In terms of love of learning, we found that introductory electromagnetism students are generally well motivated toward and passionate about learning. However, regarding the factor of owning intellectual limitations, students rank themselves as only moderately able to recognize and admit their intellectual limitations to others. These results highlight an important deficiency that needs proper attention. Porter's studies on growth mindset $[60,61]$ suggest that a view of knowledge as malleable, rather than stagnant or only coming from authority, can improve students' understanding of the importance of disclosing intellectual limitations, which in turn is beneficial for furthering one's knowledge. 
Importantly, our survey findings extend prior IH research by uncovering an important issue related to appropriate discomfort with limitations that, to our knowledge, has not been examined or documented by others. Namely, students have the most difficulty with IH when it comes to this factor both internally and in the presence of others. Overall, it is apparent from our survey results that while these students might be somewhat able to recognize and accept their limitations, they are disproportionately preoccupied with them.

Findings from student reflections and observations related to love of learning substantiated the strong survey responses to this factor's statements. Most instantiations we observed suggest that students want to reconcile confusion or correct course in order to understand how to approach problems or assignments, even if their initial ideas are mistaken. Moreover, we identified instantiations of $\mathrm{IH}$ such as seeking external help, analyzing evidence, and argumentation that align well with current frameworks for high-quality science education [62]. These findings are also consistent with the principles in Engle and Conant's engagement framework related to agency and authority [21] and provide concrete examples of students' enactments of these principles that should be supported and encouraged.

Despite these positive results, we also uncovered evidence of a lack of $\mathrm{IH}$ with respect to love of learning that hampers students' ability to transfer their learning to new situations. Specifically, for some students the sole driver of their efforts is to arrive at the right solution instead of understanding the process to get there [63]. This finding is consistent with Porter's observation [61] that veering students away from a superfluous obsession with correct answers may not only help cultivate a growth mindset but also foster $\mathrm{IH}$ in the classroom.

In terms of owning intellectual limitations, we identified three particular actions students take during group work that indicate proper handling of intellectual limitations. Our findings regarding acknowledging and disclosing limitations to others are consistent with the literature on group work practices that support physics learning [13,14,27]. Our findings also suggest a potential expansion of these practices to include a willingness to revise beliefs in the face of inconsistent evidence [12]. Such a disposition results in higher self-awareness about personal knowledge [38]. These results thus contribute to the literature on "what we do not know" by identifying students' other-oriented instantiations for owning their intellectual limitations that serve as an advantageous complement to self-oriented metacognitive skills $[14,16,17]$.

In addition, the OIL factor of $\mathrm{IH}$ allowed us to single out actions our students engage in that can hinder productive discussions, such as pretending to know. While this could be a sign of awareness of a cognitive gap, it is antithetical to the stance taken by scientists. Indeed, Watkins and colleagues [13] recommend that students explicitly take on a position of not knowing to allow the group to make progress and advance knowledge. Additionally, we uncovered that students may act in overconfident ways and portray a sense of superiority despite their intellectual limitations. This finding directly aligns with work on inchargeness $[26,64,65]$, especially when it negatively affects students' agency in group discussions and potentially sabotages equitable discussions. It may also be the case that group members feel uncomfortable challenging the ideas of a socially dominant peer, hindering their contribution to discussion and perpetuating discomfort with limitations [66]. Understanding that some students struggle with these behaviors is important because these could curtail our efforts to engage them in authentic scientific practices $[67,68]$ and may help inform the design of opportunities for students to learn how to properly handle these tendencies.

Instantiations related to appropriate discomfort with limitations uncovered plausible reasons behind the low survey responses on items related to this factor. Emotions and change in confidence provided evidence about our participants' negative affective reactions when faced with knowledge gaps during group work, yet our students' redirection of their confidence indicated a desire to find a resolution. These results are consistent with the findings of a study about physics problem solving in which students unconfident in their answers became more cognizant of their misunderstanding, spending more time focusing on the task [69]. Based on our evidence of emotions however, instructors should be judicious about active learning strategies such as cold calling, since, despite improving learning gains, these instructional moves may increase student anxiety by exposing weaknesses in front of a large audience [70].

The wide dispersion of survey responses to ADL statements could be explained in part by the two diametrically opposed instantiations of engagement. When faced with cognitive shortcomings, students described either taking a lead in the discussion that ensues or completely withdrawing from it. While the former response is in line with the disposition of not knowing [13], we hypothesize that the latter is evidence of intellectual servility if the student is afraid to reveal their limitations. Students taking too much of a reserved or disengaged role can lead to diffidence and a reluctance to take academic risks that are necessary for scientific inquiry [71]. Indeed, an intellectually servile student may be "so preoccupied with their limitations, he or she struggles to do anything about them" [45] (p. 185). However, a limitation of our observations is the difficulty

in linking observable behaviors to cognitive processes. For instance, another interpretation of this passive role is simply that students need time to think about how their ideas differ from what they hear in a discussion before engaging further. Disentangling these two possibilities warrants further study.

In addition, our findings related to engagement expand the research on epistemic distancing, providing an internal 
construct that affects how students act in conversations about topics they do not fully grasp. Moderate hesitancy to engage in a discussion may be regarded as appropriate discomfort with limitations if a student cautiously alters their engagement based on their knowledge. This may take the form of actively participating in the discussion, but presenting one's ideas with hedges such that others are still invited to contribute and critique ideas [27]. In this sense, epistemic distancing is one way that $\mathrm{IH}$ can be enacted in group conversations.

Our findings as a whole suggest that instructors wishing to engage students in productive collaborative practices [21-23] must foster classroom spaces that value positions of uncertainty and reduce social risks to students voicing their limitations. Students can benefit from learning environments that encourage them to voice confusion and/or express what they do not know or understand as well as provide guidance about how to appropriately handle these gaps. An example of what the former may look like in practice can be found in the work by Conlin and Scherr [27], specifically the interaction in the blue group between a group of students and the teaching assistant. In this episode, the teaching assistant explicitly encourages the group to discuss ideas they are unsure of, allowing for the students to feel more comfortable with not knowing and opening up an instructive discussion of a challenging concept. In terms of handling shortcomings, instructors should avoid the image of authoritative knowledge holders [72] and instead explicitly acknowledge the struggles that come with learning even for experts, readily recognizing and verbalizing their own limitations and indicating the benefits of doing so to advance understanding. Exposing students to these approaches to what we do not know may provide a model for IH that students themselves can follow [61].

\section{CONCLUSION}

In this paper, we offer new insights into the study of introductory physics group interactions with a focus on situations where students' ideas are challenged and students must engage in productive discussions with others to resolve the issue. We have introduced intellectual humility as a limitations-owning construct with three defining factors to help us better understand and distinguish the nuanced instantiations that play a role in enabling or hindering such discussions. We also presented the operationalization of IH for physics education research using a mixed methods study of data from introductory electromagnetism students. Our findings suggest that students already espouse strong levels of IH in their value of how other-focused they and their peers are [12], a value that we should not underestimate.

With this in mind, however, our findings clearly point to students' discomfort with limitations as an area in need of our attention, suggesting that we should curate learning spaces that welcome discussions around uncertainties.
Taken together, our study suggests that learning spaces should offer students the opportunity to (a) learn to effectively cope with and verbalize shortcomings in their own reasoning processes [12], (b) become aware of the intellectually humble attitudes and behaviors that are conducive to productive discussions [36], and (c) develop the mindsets and skills for appropriately managing their limitations to successfully collaborate with and position themselves among others when solving physics problems [13]. Fostering classroom environments in which students are not hesitant to position themselves as not knowing may open up more opportunities for productive and authentic scientific work $[13,23]$.

While our study offers valuable insights into students' engagement during scientific inquiry, there are two potential limitations to our work that must be noted. First, our small and predominantly male sample may narrow the spectrum of perspectives we saw in the data and therefore confine the generalizability of our findings. Nonetheless, we believe our evidence from surveys and qualitative insights reveals important instantiations of IH in the context of physics learning. Future research that follows our methods on a larger and/or more heterogeneous sample will be beneficial to help us understand whether our findings extend to the broader population of introductory physics students. Second, we only had access to aggregate demographic information about the participants. Specific demographic data would have allowed us to connect what each participant had to say with underlying qualities they may have had, enabling potential comparisons or patterns to be drawn. Future work that empirically examines IH should include analysis specifically geared toward understanding any variations in IH across demographics (e.g., gender, race, socioeconomic status). Such studies would help uncover whether IH manifests differently or inequitably in underrepresented or marginalized students and offer insights into how to improve collaborative learning experiences for all students.

Although PER studies have addressed aspects of group collaboration, the problem persists of how to engage students in group work with appropriate self-awareness, adequate argumentation skills, openness to the views of others, and willingness to negotiate their ideas [73]. While Engle and Conant outline the Productive Disciplinary Engagement framework [21,22] as big picture conditions for productive scientific inquiry, intellectual humility offers a promising outlook on how we can attend to more specific hindrances to productive group work, capturing most of the tenets that researchers have deemed crucial. Addressing student perceptions and skills related to IH will enable us as educators to guide our students in ways that more authentically resemble scientific practices, including helping our students handle their intellectual limitations during collaboration. We hope that our work provides a basis that motivates others in the PER community to explore the 
potential of intellectual humility for educational research and practice.

\section{ACKNOWLEDGMENTS}

We thank Jason Hancock and Manuela Wagner for providing meaningful suggestions about the study design and Belter Ordaz Mendoza and Diego Valente for assisting with data collection. We also appreciate the helpful feedback of Natasha Holmes and Anna Phillips on the written manuscript.

\section{APPENDIX A: REFLECTION QUESTIONNAIRE 1}

Please take a minute and think about your experiences in this course so far and reflect on the following questions in the space below:

1. What resources in the classroom enable or hinder you in learning physics concepts?

2. Are there any resources in the classroom that you would attribute to making you more (or less) prone to engage in academic discussions with your group members? If so, which ones and how?

3. What attitudes and behaviors of your peers enable or hinder you in learning physics concepts?

4. What attitudes and behaviors of your peers make you more (or less) prone to engage in an academic conversation with them?

5. Which labs or types of labs are most helpful in learning the physics content? Why?
6. Which labs or in-class activities help you engage most successfully with your peers? Why?

\section{APPENDIX B: REFLECTION QUESTIONNAIRE 2}

Please take a minute and think about your experiences in this course so far and reflect on the following questions in the space below:

1. When you are solving problems in a group during class time, do you try to identify and correct any gaps in your knowledge? Why and how?

2. What do you do if you feel that you do not know enough to engage in academic conversations with your peers during class time?

3. If you or other people in your group disagree with an approach, strategy, or solution, do you take any steps to resolve it? If so, describe. If not, how do you choose how to proceed?

4. How do you feel when your approach or response in the group work is challenged or proven wrong?

5 . When you are proven wrong while working in groups, how does that affect your engagement in further discussions?

6. With the previous five questions in mind, what attitudes and behaviors of your peers enable or hinder you in learning physics concepts?

7. Are there other comments in line with the previous six questions that you would like to add?
[1] National Research Council, How People Learn: Brain, Mind, Experience, and School, Expanded ed. (National Research Council, Washington, DC, 2000).

[2] J. Osborne, Arguing to learn in science: The role of collaborative, critical discourse, Science 328, 463 (2010).

[3] S. Freeman, S. L. Eddy, M. McDonough, M. K. Smith, N. Okoroafor, H. Jordt, and M. Pat Wenderoth, Active learning increases student performance in science, engineering, and mathematics, Proc. Natl. Acad. Sci. U.S.A. 111, 8410 (2014).

[4] L. Deslauriers, E. Schelew, and C. Wieman, Improved learning in a large-enrollment physics class, Science 332, 862 (2011).

[5] D. E. Meltzer and R. K. Thornton, Resource letter alip-1: active-learning instruction in physics, Am. J. Phys. 80, 478 (2012).

[6] N. Lasry, E. Mazur, and J. Watkins, Peer instruction: From harvard to the two-year college, Am. J. Phys. 76, 1066 (2008).

[7] V. Sampson and D. Clark, The impact of collaboration on the outcomes of scientific argumentation, Sci. Educ. 93, 448 (2009).
[8] M. K. Smith, W. B. Wood, W. K. Adams, C. Wieman, J. K. Knight, N. Guild, and T. Tin Su, Why peer discussion improves student performance on in-class concept questions, Science 323, 122 (2009).

[9] J. F. Zipp, Learning by exams: The impact of two-stage cooperative tests, Teach. Sociol. 35, 62 (2007).

[10] E. Marie Furtak and W. R. Penuel, Coming to terms: Addressing the persistence of hands-on and other reform terminology in the era of science as practice, Sci. Educ. 103, 167 (2019).

[11] E. Van Zee and J. Minstrell, Using questioning to guide student thinking, J. Learn. Sci. 6, 227 (1997).

[12] D. Whitcomb, H. Battaly, J. Baehr, and D. Howard-Snyder, Intellectual humility: Owning our limitations, Philos. Phenomenol. Res. 94, 509 (2017).

[13] J. Watkins, D. Hammer, J. Radoff, L. Z. Jaber, and A. M. Phillips, Positioning as not-understanding: The value of showing uncertainty for engaging in science, J. Res. Sci. Teach. 55, 573 (2018).

[14] T. O. B. Odden and R. S. Russ, Sensemaking epistemic game: A model of student sensemaking processes in 
introductory physics, Phys. Rev. Phys. Educ. Res. 14, 020122 (2018).

[15] M. D. Koretsky, M. Vauras, C. Jones, T. Iiskala, and S. Volet, Productive disciplinary engagement in high- and low-outcome student groups: Observations from three collaborative science learning contexts, Res. Sci. Educ. 51, 159 (2021).

[16] J.H. Flavell, Metacognition and cognitive monitoring: A new area of cognitive-developmental inquiry, Am. Psychol. 34, 906 (1979).

[17] G. Schraw and D. Moshman, Metacognitive theories, Educ. Psychol. Rev. 7, 351 (1995).

[18] J. G. Borkowski, M. Carr, and M. Pressley, Spontaneous strategy use: Perspectives from metacognitive theory, Intelligence 11, 61 (1987).

[19] R. Garner, When children and adults do not use learning strategies: Toward a theory of settings, Rev. Educ. Res. 60, 517 (1990).

[20] R. Garner and P. A. Alexander, Metacognition: Answered and unanswered questions, Educ. Psychol. 24, 143 (1989).

[21] R. A. Engle and F. R. Conant, Guiding principles for fostering productive disciplinary engagement: Explaining an emergent argument in a community of learners classroom, Cognit. Instr. 20, 399 (2002).

[22] R. A. Engle, The productive disciplinary engagement framework: Origins, key concepts, and developments, in Design Research on Learning and Thinking in Educational Settings: Enhancing Intellectual Growth and Functioning (Routledge, London, 2011), pp. 161-200.

[23] A. McLean Phillips, J. Watkins, and D. Hammer, Problematizing as a scientific endeavor, Phys. Rev. Phys. Educ. Res. 13, 020107 (2017).

[24] M. Sundstrom, A. McLean Phillips, and N. G. Holmes, Problematizing in inquiry-based labs: How students respond to unexpected results, in Proceedings of the 2020 Physics Education Research Conference, virtual conference (AIP, New York, 2020).

[25] A. McLean Phillips, M. Sundstrom, D. G. Wu, and N. G. Holmes, Not engaging with problems in the lab: Students' navigation of conflicting data and models, Phys. Rev. Phys. Educ. Res. 17, 020112 (2021).

[26] T. Huynh, A. P. Jambuge, J. T. Laverty, and E. C. Sayre, Positioning in groups: The roles of expertise and being in charge, in Proceedings of the 14th International Conference of the Learning Sciences (ICLS), edited by M. Gresalfi and I. S. Horn, Vol. 2 (International Society of the Learning Sciences, Nashville, Tennessee, 2020), pp. 757-758.

[27] L. D. Conlin and R. E. Scherr, Making space to sensemake: Epistemic distancing in small group physics discussions, Cognit. Instr. 36, 396 (2018).

[28] D. E. Davis, J. N. Hook, E. L. Worthington Jr., D. R. Van Tongeren, A. L. Gartner, D. J. Jennings, and R. A. Emmons, Relational humility: Conceptualizing and measuring humility as a personality judgment, Cognit. Instr. 36, 225 (2011).

[29] D. E. Davis, K. G. Rice, S. McElroy, E. Choe, D. R. Van Tongeren, and J.N. Hook, Distinguishing intellectual humility and general humility, J. Positive Psychol. 11, 215 (2016).
[30] S. E. McElroy, K. G. Rice, D. E. Davis, J. N. Hook, P. C. Hill, E. L. Worthington Jr., and D. R. Van Tongeren, Intellectual humility: Scale development and theoretical elaborations in the context of religious leadership, J. Psychol. Theology 42, 19 (2014).

[31] A. Tanesini, Intellectual servility and timidity, J. Philos. Res. 43, 21 (2018).

[32] A. Tanesini, Calm down, dear: Intellectual arrogance, silencing and ignorance, in Aristotelian Society Supplementary Volume (Oxford University Press, New York, 2016), Vol. 90, pp. 71-92.

[33] A. Tanesini, Reducing arrogance in public debate, in Virtues in the Public Sphere: Citizenship, Civic Friendship and Duty (Routledge, London, 2018), pp. 23-38.

[34] A. Tanesini, Arrogance, anger and debate, Symposion 5, 213 (2018).

[35] R. C. Roberts and W. Jay Wood, Humility and epistemic goods, in Intellectual Virtue: Perspectives from Ethics and Epistemology, edited by M. DePaul and L. Zagzebski (Oxford University Press, New York, NY, 2013), pp. 257-279.

[36] A. Tanesini, Intellectual humility as attitude, Philos. Phenomenol. Res. 96, 399 (2018).

[37] S. A. Deffler, M. R. Leary, and R. H. Hoyle, Knowing what you know: Intellectual humility and judgments of recognition memory, Personality Indiv. Diff. 96, 255 (2016).

[38] E. J. Krumrei-Mancuso, M. C. Haggard, J. P. LaBouff, and W. C. Rowatt, Links between intellectual humility and acquiring knowledge, J. Positive Psychol. 15, 155 (2020).

[39] W. Hare, Open-mindedness in moral education: Three contemporary approaches, J. Moral Educ. 16, 99 (1987).

[40] H. Battaly, Responsibilist virtues in reliabilist classrooms, in Intellectual Virtues and Education (Routledge, New York, 2015), pp. 163-183.

[41] T. Porter, K. Schumann, D. Selmeczy, and K. Trzesniewski, Intellectual humility predicts mastery behaviors when learning, Learning Indiv. Diff. 80, 101888 (2020).

[42] R. H. Hoyle, E. K. Davisson, K. J. Diebels, and M. R. Leary, Holding specific views with humility: Conceptualization and measurement of specific intellectual humility, Personality Indiv. Diff. 97, 165 (2016).

[43] E. J. Krumrei-Mancuso and S. V. Rouse, The development and validation of the comprehensive intellectual humility scale, J. Personality Assess. 98, 209 (2016).

[44] M. R. Leary, K. J. Diebels, E. K. Davisson, K. P. JongmanSereno, J. C. Isherwood, K. T. Raimi, S. A. Deffler, and R.H. Hoyle, Cognitive and interpersonal features of intellectual humility, Personality Social Psychol. Bull. 43, 793 (2017).

[45] M. Haggard, W. C. Rowatt, J. C. Leman, B. Meagher, C. Moore, T. Fergus, D. Whitcomb, H. Battaly, J. Baehr, and D. Howard-Snyder, Finding middle ground between intellectual arrogance and intellectual servility: Development and assessment of the limitations-owning intellectual humility scale, Personality Indiv. Diff. 124, 184 (2018).

[46] J. Wilson, The development of the studio classroom, in Technology Enhanced Learning: Opportunities for Change, edited by P. Goodwin (Lawrence Erlbaum, Mahwah, NJ, 2002), pp. 265-288. 
[47] J. W. Creswell, V. L. Plano Clark, M. L. Gutmann, and W. E. Hanson, An expanded typology for classifying mixed methods research into designs, in Handbook of Mixed Methods in Social and Behavioral Research, edited by A. Tashakkori and C. Teddlie (Sage, Thousand Oaks, CA, 2003), pp. 209-240.

[48] Dr. P. Hinton, P. R. Hinton, I. McMurray, and C. Brownlow, SPSS explained (Routledge, London, 2004).

[49] R. Tesch, Qualitative Research Analysis Types and Software Protocols (The Falmer Press, Hampshire, United Kingdom, 1990).

[50] M. B. Miles and A. Michael Huberman, Qualitative Data Analysis: An Expanded Sourcebook (Sage, Thousand Oaks, CA, 1994).

[51] M. Q. Patton, Qualitative research \& evaluation methods: Integrating theory and practice (Sage, Thousand Oaks, CA, 2014).

[52] J. L. Campbell, C. Quincy, J. Osserman, and O. K. Pedersen, Coding in-depth semistructured interviews: Problems of unitization and intercoder reliability and agreement, Sociological Methods Res. 42, 294 (2013).

[53] H.-F. Hsieh and S.E. Shannon, Three approaches to qualitative content analysis, Qualitative Health Res. 15, 1277 (2005).

[54] D. L. Morgan, Qualitative content analysis: A guide to paths not taken, Qualitative Health Res. 3, 112 (1993).

[55] K. Musante DeWalt and B. R. DeWalt, Participant Observation: A Guide for Fieldworkers (AltaMira Press, Walnut Creek, CA, 2002).

[56] D. R. Thomas, A general inductive approach for analyzing qualitative evaluation data, Am. J. Eval. 27, 237 (2006).

[57] S. Merriam and E. Tisdell, Qualitative Research: A Guide to Design and Implementation (John Wiley \& Sons, Inc., San Francisco, 2016).

[58] D. Whitcomb, Some epistemic roles for curiosity, in Technology Enhanced Learning: Opportunities for Change, edited by I. Inan, L. Watson, D. Whitcomb, and S. Yigit (Rowman and Littlefield, Lanham, MD, 2018), pp. 217-238,

[59] J. S. Spiegel, Open-mindedness and intellectual humility, Theory Res. Educ. 10, 27 (2012).

[60] T. Porter and K. Schumann, Intellectual humility and openness to the opposing view, Self Identity 17, 139 (2018).

[61] T. Porter, Intellectual Humility, Mindset, and Learning (Stanford University, Stanford, CA, 2015).

[62] National Research Council, A Framework for K-12 Science Education: Practices, Crosscutting Concepts, and Core Ideas (National Academies Press, Washington, DC, 2012).
[63] J. Watkins and E. Mazur, Retaining students in science, technology, engineering, and mathematics (stem) majors, J. Coll. Sci. Teach. 42, 36 (2013), https://www.jstor.org/ stable/43631580.

[64] B. A. Archibeque, M.-B. Kustusch, F. Genz, S. Franklin, and E. C. Sayre, Qualitative measures of equity in small groups, in Proceedings of the 13th International Conference of the Learning Sciences (ICLS), London, U.K., edited by J. Kay and R. Luckin, Vol. 2 (International Society of the Learning Sciences, London, U.K., 2018).

[65] M. Bridget Kustusch, E. C. Sayre, and S. Franklin, Identifying shifts in agency by analyzing authority in classroom group discussion, in Proceedings of the 13th International Conference of the Learning Sciences (ICLS), London, U.K., edited by J. Kay and R. Luckin, Vol. 3 (International Society of the Learning Sciences, London, U.K., 2018).

[66] L. St. Clair and M. Tschirhart, When and where? Facilitating group work beyond the borders of the classroom, J. Manage. Educ. 26, 449 (2002).

[67] L. K. Berland, C. V. Schwarz, C. Krist, L. Kenyon, A. S. Lo, and B. J. Reiser, Epistemologies in practice: Making scientific practices meaningful for students, J. Res. Sci. Teach. 53, 1082 (2016).

[68] R. Lehrer and L. Schauble, Seeding evolutionary thinking by engaging children in modeling its foundations, Sci. Educ. 96, 701 (2012).

[69] S. Küchemann, P. Klein, H. Fouckhardt, S. Gröber, and J. Kuhn, Students understanding of non-inertial frames of reference, Phys. Rev. Phys. Educ. Res. 16, 010112 (2020).

[70] K. M. Cooper, V. R. Downing, and S. E. Brownell, The influence of active learning practices on student anxiety in large-enrollment college science classrooms, Int. J. STEM Educ. 5, 1 (2018).

[71] J. D. Bransford and M. Suzanne Donovan, Scientific inquiry and how people learn, in How Students Learn: History, Mathematics, and Science in the Classroom, edited by S. M. Donovan and J. D. Bransford (National Academies Press, Washington, DC, 2005), pp. 397-420.

[72] S. Olitsky, Facilitating identity formation, group membership, and learning in science classrooms: What can be learned from out-of-field teaching in an urban school?, Sci. Educ. 91, 201 (2007).

[73] E. Alexopoulou and R. Driver, Small-group discussion in physics: Peer interaction modes in pairs and fours, J. Res. Sci. Teach. 33, 1099 (1996). 